\title{
Impacts Of National Institutions On Trust-Outcome Relation In R\&D Alliances
}

\author{
Le Manh Duc ${ }^{1}$, Shawkat Kamal ${ }^{2}$ \\ ${ }^{1}$ (Project Management Department/ University of Transport and Communications, Vietnam) \\ ${ }^{2}$ (Department of Business Administration/ Green University of Bangladesh, Bangladesh)
}

\begin{abstract}
Although it has been found that trust, in general, are beneficial to $R \& D$ alliances; the effect surrounding national institutions (i.e. formal versus informal) have on the level of benefit observed has often been left unattended. In this paper, we examine how various national institutions; intellectual property protection and individualism in particular, impact interorganizational trust and its benefits to alliance performance. We propose that the positive effect of trust on alliance performance magnifies under weaker formal institutional contexts. Further we propose that national cultural values, particularly individualistic orientation; diminishes the level of trust observed in $R \& D$ alliances across countries.
\end{abstract}

Key Words: Cultural Orientation, National Institutions, R\&D Alliances, Trust

\section{Introduction}

R\&D alliances can be defined as voluntary collaborations between independent firms that involve sharing and/or co-development of technologies, products or services [1 and 2]. R\&D alliances have become a useful strategic device as they proliferate in technology-intensive industries [2]. Such alliances encourage interactive learning through mutual transferring of knowledge and technological capabilities between partnering firms; and often these activities are ideal ways to spread the risk and cost of innovations and technological development. So it is not unnatural that studies indicated that R\&D alliances are critical to firms' survival and profitability in technology-intensive industries [3].

The smooth functioning of strategic alliances relies heavily on interfirm relationship management; hence, it is without surprise that interorganizational trust is highlighted as a critical tool in alliance governance. While enjoying access to partners' technological capabilities, firms also expose their proprietary knowledge to their partners' opportunism. Trust between the partners may allay the fear of alliance partners' opportunistic behaviors. Studies have mentioned a wide rage of positive outcome of trust on interfirm relationships. For example, trust lowers transaction costs, increases sales and returns on investment, and facilitates knowledge transfer and leveraged capabilities [4, 5, 6, and 7]. Moreover, trust also facilitates shared values, routines, and ways of working between partners which are fundamental conditions for effective sharing of technological knowledge.

In this paper, we examine how various national institutions influence interorganizational trust and the impact they have on $R \& D$ alliance performance. Particularly, we argue that the positive effect of trust on alliance performance magnifies under weaker formal institutional contexts. Meanwhile, individualistic orientation of a society reduces the level of trust observed in these interfirm relations. In the next part, we will first review the extant literature on interorganizational trust in R\&D alliance and position our research question. Then, we will develop arguments which would lead to a few propositions that we believe might be testable if relevant data are available. In the final section we will discuss the potential contributions and limitations of the paper.

\section{Literature Review}

It is becoming clear among scholars from a various disciplines (e.g., strategic management, sociology, and economics) that interorganizational trust is a critical factor for interfirm relation management such as the case of strategic alliances [8]. Among studies on strategic alliances, there is a broad stream that focuses on investigating the role of interfirm trust in dyadic or multi-party collaborations. Interorganizational trust is defined as "the expectation held by one firm that another will not exploit its vulnerabilities when faced with the opportunity to do so" [9].

Zaheer and Harris, in their 2006 article on interorganizational trust, propagate the idea that there are three typical lines of research about interorganizational trust in strategic alliances. The first one examines the nature of interorganizational trust. Researchers fragmented this rather broad concept, and tried to look at interorganizatonal trust into fine-grained dimensions. For example, interorganizational trust can be seen as composed of goodwill-based trust and competence-based trust [10]. Goodwill-based trust reflects beliefs about a partner's intention to complete his obligations. In contrast, a confidence about a partner's ability to finish his 
obligations is competence-based trust. Fundamentally, trust is reciprocal and long-term. The second stream of research on interorganizational trust focuses on how trust is developed. Researchers have suggested several initial conditions of trust creation, for example, flexibility, information exchange, perception of fairness, and mutual efforts [11,12, and 13]. Trust is incrementally built as partners engage in multiple alliances with each other over time [14]. The third stream of research investigates the role and outcome of trust in strategic alliances. Trust can be considered as a form of organizing and a substitute for formal contractual governance. It can lead to lowered transaction costs, increased sales, knowledge transfer and leveraged capabilities [4, 5, and 7]. In general, trust is perceived as beneficial to strategic alliances.

Even though there are extensive findings in prior studies for the overall positive effect of interorganizational trust, researchers also recognized that trust may not always enhance alliance outcomes [15]. Carson et al., [16] proposed that the beneficial effect of trust on performance in vertical R\&D collaborations is strengthened with information-processing abilities of partner firms. In their seminal work, Krishnan et al., [9] found that the performance enhancing potential of trust magnifies under behavior uncertainty but reduces under environmental uncertainty. Particularly, interorganizational trust mitigates the likelihood that a focal firm will negatively interpret its partner actions. This is critical for openness in knowledge sharing alliances especially when there is uncertainty about partner behaviors. However, trust restrains a vigilant market investigation because partnering firms are often overconfident as far as information sharing between each other is concerned. Beneficial effect of trust on strategic alliances is, hence, reduced when environmental uncertainty is strong. In general, these studies propose that the trust-performance relation in R\&D alliance is complicated, and the benefits derived from trust are contingent on various other factors.

Following the line of research in finding the contingencies and limits of trust to alliance outcome, several studies with empirical evidences imply that institutional factors across national boundaries might influence the development of trust, its effects and consequences on business collaborations [8]. Some scholars also argue that trust in interfirm relationships depends on shared and institutionalized expectations or practices shaped by the institutional context in which the focal firms are embedded. Institutional differences might induce different levels of trust or influence its effects and benefits [17]. It is further argued that differences in value systems, culture, and formal institutions across nations influence initial trust between alliance partners. In different societies, a partner may have greater or lesser degrees of initial trust on the other partner and also its perception of trust differs. Moreover, the differences in institutional contexts might also impact trust's effects and benefits [18]. Sako [12] found that national context accounts for the difference in the effects of trust on collaborative performance between suppliers and automakers in seven countries: Japan, U.S.A., Germany, Britain, France, Spain, and Italy.

These above studies have suggested that institutional contexts matter without much discussing the underlying theories. We just observe the surface which is the difference in trust and performance consequences in several countries. It is not clear exactly how each component of an institutional environment, both informal and formal, impact trust-outcome relation. Each component of institutions might impact trust and its resulting consequences differently. In this paper, we would like to investigate specifically how formal institutions and cultural values (individualism vs. collectivism) across nations influence interorganzational trust and its effect on performance in $R \& D$ alliances.

\section{Trust and Alliance Performance}

\section{Proposition Development}

Prior literature has suggested two main mechanisms that explain how trust positively influence on R\&D alliance outcome: (i) trust is considered a "self-enforcing" safeguard or governance structure that minimize alliances' transaction cost, (ii) trust stimulates partners to engage in "non-contractible" and relation specific behaviors that create values for alliances [5, 12, and 19]. Figure 1 summarizes the two mechanisms.

R\&D alliances are characterized by high opportunism from participating firms that increases transaction costs. Partners are required to share and expose their own technological capabilities and knowledge to each other. Firms run a high risk of losing its core technological assets due to partner opportunism. It is suggested that firms then need to adopt appropriate contractual governances to mitigate these concerns. Particularly, the higher the risk of losing proprietary assets, the more hierarchical-related contracts will be employed (e.g., equity-based alliances). Nevertheless, many studies have suggested trust-based governance as a substitute for these formal governance contracts. Trust can be an effective governance mechanism as it alleviates concerns about partner opportunism. For example, trust defuses inter-partner conflict as trustful partners interpret each other's ambiguous actions in a constructive manner favorable to the stability of the alliance relationship [19 and 20]. Hill [21] argued that trust reduces transaction costs because it eliminates the need for writing, monitoring, and enforcing formal contract. Similarly, Dyer [5] proposed that trust-based governance enable lower transaction costs than other contract-based governances in alliance. He further claimed that trust is a "self-reinforcing agreement" in interfirm collaborations. 


\section{FIGURE 1}

How Does Trust Enhance Alliance Performance?

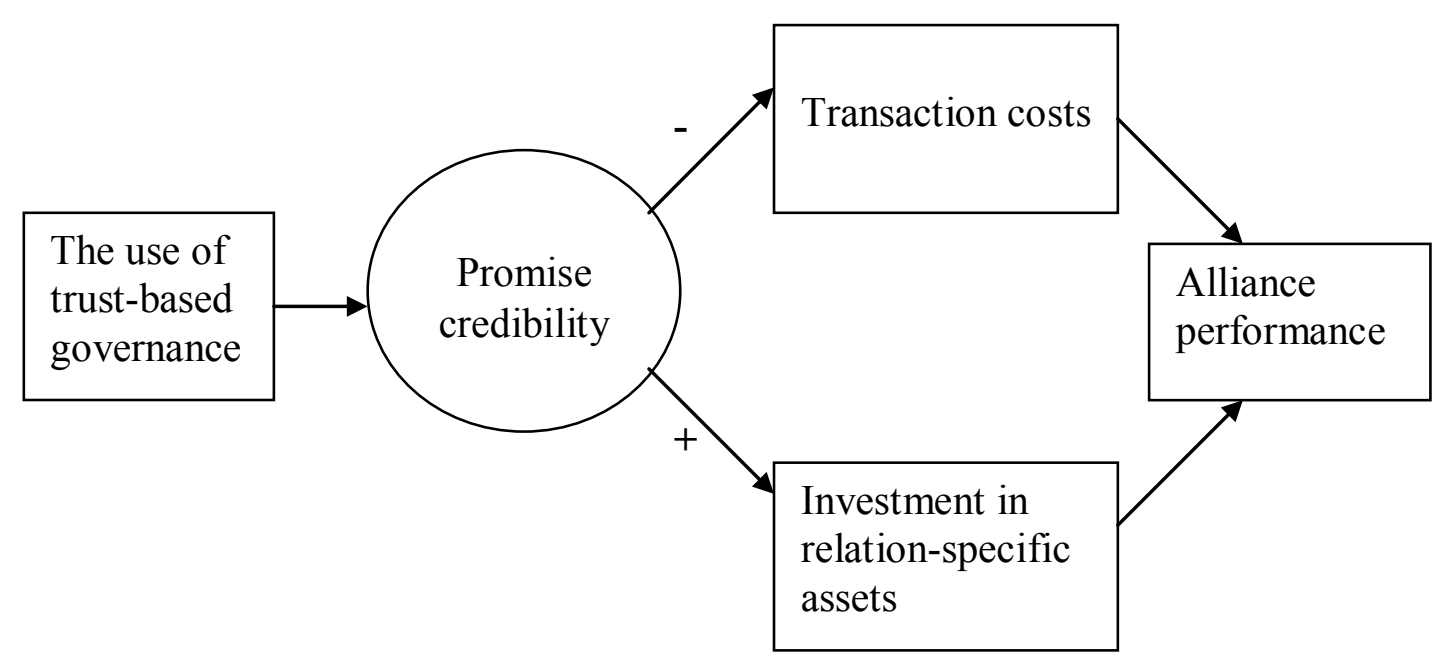

* This figure is adapted from Dyer (1997)

Trust further creates values by stimulating partners to engage in transaction specific investments. Sako [12] found that trustful partners commit themselves and make contributions to alliance relationship that go beyond contractual obligations. Dyer [5] found that Japanese automakers intensively form trust-based relations with their suppliers through repeated ties and norms sharing. In their turn, these suppliers engage more in value engineering and value analysis (i.e., initiatives and endeavors to continuously lower production costs of the transaction-specific components that they supply). Through trust-based governance, alliance partners can simultaneously obtain the twin benefits derived from "high asset specificity and low transaction costs".

Trust further facilitates accumulation of interorganizational learning routines. These routines enable partners to identify valuable knowledge and transfer it effectively across firm boundaries in R\&D alliances [7]. By engaging in multiple alliances with each other, each partner develops a refined understanding of other's organization and a set of routines to instruct the way they interact among themselves. These interorganizational routines defuse coordination or information-gathering issues in alliances and enhance iterative learning and alliance performance [22]. Hence, we come out with our first proposition as follows -

\section{Proposition 1: Trust is positively related to alliance performance.}

\section{The Strength of Formal Institutions as a Moderator}

In this part, we argue that the benefit of trust towards alliance performance is strong in weak formal institution contexts and weak in strong formal institution settings. We particularly examine one component of formal institutions important for management of R\&D alliances: intellectual property protection. Intellectual property protection refers to the rigor and enforcement of intellectual property laws (e.g., patents and copyrights) that safeguards proprietary intellectual assets.

A partner firm in a weak intellectual property protection context is in general more concerned about opportunistic behaviors of its partner in R\&D alliances. In such a situation, a partner firm feels less certain that the partner will not appropriate its proprietary technological assets. This intensifies a partner firm's tendencies to protect its own technological knowledge at the cost of hindering and reducing the alliance productivity and outcomes. The synergistic benefits of R\&D alliances are hampered as partners are detracted from contributing fully to the functioning of these alliances [23].

From figure 1, we can observe that trust alleviates these exploitative concerns of proprietary resources in R\&D alliances. Kale et al. [2] argue that trust raises a mutual confidence in the partners that no partner in the alliance will abuse the other's vulnerabilities. Armed with beliefs in goodwill and fairness of the other, each firm in an alliance often creates formal and informal codes of conduct that restrict misbehaviors and respect the boundaries of its partner's proprietary assets. Partners then tend to contribute the substantive resources and information to enhance collaborative performance. Kale et al. [2] confirm that trust help firms successfully balance the dual job of acquisition of new knowledge and protection of technological assets in R\&D alliance. 
Trust is more effective where the intellectual property protection is weak, because it mitigates exploitative concerns about technology resources and creates mutual respects that counteract any failure to cooperate and in turn enhances the performance of the alliance. In strong intellectual property protection contexts, conversely, the appropriation of technological assets is less likely to be a serious concern for partners in R\&D alliances. Strict laws and legal sanctions are readily available to alleviate a partner's uncertainties about the other's opportunism. Put in these contexts, the benefits of interfirm trust are lower.

Applying a game theoretical model of relationship building, Hwang [24] has proved that trust has greater impact on collaboration outcome in a society when formal institution is weaker. Particularly, the derivative of the additional transaction value enabled by trust with respect to strength of formal institutions is negative. Hence, trust and formal institutions may act as substitutes because the value of trust reduces when formal institutions are strong. Welter et al. [25] observed that in strong institutional contexts like Germany, trust plays only a secondary role in interfirm relations. Conversely, where institutional supports are weak, trust plays a more prominent role. So we offer our next proposition -

Proposition 2: The strength of intellectual property protection negatively moderates trust-performance relation in $R \& D$ alliances.

\section{Individualism and various levels of trust in R\&D alliances}

In this part, we argue that differences in individualistic orientation of societies will influence the level of trust in their R\&D collaborations. Individualism characterizes "societies in which the ties between individuals are loose: everyone is expected to look after himself or herself and his or her immediate family. Collectivism as its opposite pertains to societies in which people from birth onwards are integrated into strong, cohesive ingroups, which throughout people's lifetime continue to protect them in exchange for unquestioning loyalty" [26]. People/firms from various cultures differ from each other in their degrees of focus on either individual or collective pursuits that may strongly influence the level of trust. In other words, the level of trust varies across national cultures and cultural differences often determine the level of trusts observed in individuals/firms.

People from individualistic cultures love independence from any kind of group affiliation, whereas those from collective cultures value long-term relations [27]. Similarly, firms of collective societies desire forming repeated and long-term collaborations; however, those of individualistic societies favor spot collaborations and emphasize less on social capital brought by close relationship with partners. As trust is derived from repeated relations, it is valued less in individualistic cultures than in collectivistic ones. In the collectivistic society of Japan, in general a high level of trust is observed in the business relations [28]. Trust is supported by strongly institutionalized practices that facilitate cooperative behaviors and puts a rein on opportunistic actions. Moreover, reputation of a firm's honesty is spread through social networks, which makes the practice of trust in business relations as a social norm. Hence, we expect the level of trust between partners in R\&D alliances is less in individualistic countries than in collectivist countries. This leads us to our final proposition -

Proposition 3: A culture of individualism is negatively related to the level of trust observed in $R \& D$ alliances across countries.

\section{Discussion And Conclusion}

Our theoretical work contributes to the stream of research on limits of trust by suggesting that the beneficial effect of trust on alliance performance is contingent on surrounding formal institutions. Specifically, the effect of trust on alliance performance magnifies under weaker formal institutional contexts. This proposition has an important implication for the use of trust in R\&D alliances. As the development of trust in these collaborations is costly, we might think of differentiating optimum levels of trust in different contexts. For example, the optimum level of trust required for $R \& D$ collaborations in a strong formal institutional environment should be much less than that in a weak formal institutional context.

The study also contributes to the body of knowledge on interorganizational trust by making clearer how each component of national institutions might impact trust and its impact on eventual consequences differently. We proposed the moderating effect of intellectual property protection. Meanwhile, informal cultural values may impact the variation of trust across national boundaries.

This study aimed to explore how each component of a national institutional environment might impact trust and its beneficial effect on R\&D alliances. While a nation's institutions involve a lot of factors, we only covered two ingredients that are intellectual property protection and individualism. This is the main limitation of the study. There is a lot of room for further discovery on impacts of the other institutional factors. For example, further study could investigate the role of industry norms in the relation between trust and performance. We 
believe this study will help future studies in this area and when backed by proper empirical data will bolster the arguments that we have put forward in this paper.

\section{Referencies}

[1] A. Parkhe, Strategic alliance structuring: a game theoretic and transaction cost examination of interfirm cooperation, Academy of Management Journal, 36, 1993, 794-829.

[2] P. Kale, H. Singh, and H. Perlmutter, Learning and protection of proprietary assets in strategic alliances: building relational capital, Strategic Management Journal, 21, 2000, 217-237.

[3] D. C. Mowery, J. E. Oxley, and B. S. Silverman, Strategic alliances and interfirm knowledge transfer, Strategic Management Journal, 17, 1996, 77-91.

[4] J. Mohr, R. Spekman, Characteristics of partnership success: partnership attributes, communication behavior, and conflict res olution techniques, Strategic Management Journal, 15(2), 1994, 135-152.

[5] J. H. Dyer, Effective interfirm collaboration: How firms minimize transaction costs and maximize shareholder value, Strategic Management Journal, 18(7), 1997, 535-556.

[6] Y. Luo, Contract, cooperation, and performance in international joint ventures, Strategic Management Journal, 23(10), 2002, 903919.

[7] M. Zollo, J. J. Reuer, and H. Singh. Interorganizational routines and performance in strategic alliances, Organization Science, 13(6), 2002, 701-713.

[8] A. Zaheer, and J. Harris. Interorganizational trust, in O. Shenkar and J. J. Reuer (Ed.). Handbook of strategic alliances, (California: Sage, 2006) 169-198.

[9] R. Krishnan, X. Martin, and N. G. Noorderhaven, When does trust matter to alliance performance?, Academy of Management Journal, 49, 2006, 894-917.

[10] S.S. Lui, and H. Y. Ngo, The role of trust and contractual safeguards on cooperation in non-equity alliances, Journal of Management, 30, 2004, 471-485.

[11] P.A. Aulakh, M. Kotabe, and A. Sahay, Trust and performance in cross-border marketing partnerships: A behavioral approach, Journal of International Business Studies, 27 (5), 1996, 1005-1032.

[12] M. Sako, The role of trust in Japanese buyer-supplier relationships, Ricerche economiche, XLV(2-3), 1991, 449-474.

[13] C. Howorth, P. Westhead, and M. Wright, Buyouts, information asymmetry and the family management dyad, Journal of Business Venturing, 19(4), 2004, 509-534.

[14] D. Good, Individuals, interpersonal relations and trust, in D. Gambetta (Ed.). Trust: Making and breaking co-operative relations, (New York: Basil Blackwell, 1988) 31-48.

[15] B. McEvily, V. Perrone, and A. Zaheer, Trust as an organizing principle, Organization Science, 14(1), 2003, 91-103.

[16] S. J. Carson, A. Madhok, R. Varman, and G. John, Information processing moderators of the effectiveness of trust-based governance in interfirm R\&D collaboration, Organization Science, 14(1), 2003, 45-56.

[17] C. lane, and R. Bachmann, The social constitution of trust: Supplier relations in Britain and Germany, Organization Science, 17(3), $1996,365-395$.

[18] A. Arino, J. de la Torre, and P. S. Ring, Relational quality: Managing trust in corporate alliances, California Management Review, 44(1), 2001, 109-131.

[19] A. Zaheer, B. McEvily, and V. Perrone, Does trsut matter? Exploring the effects of interorganizational and interpersonal trust on performance, Organization Science, 9(2), 1998, 141-159.

[20] J. H. Dyer, and W. Chu, The role of trustworthiness in reducing transaction costs and improving performance: Empirical evidence from the United States, Japan, and Korea, Organization Science, 14(1), 2003, 57-68.

[21] C. W. Hill, Cooperation, opportunism, and the invisible hand: Implications for transaction cost theory, Academy of Management review, 15(3), 1990, 500-513.

[22] Y. Doz, The evolution of cooperation in strategic alliances: Initial conditions or learning processes? Strategic Management Journal, $17,1996,55-83$.

[23] A. Madhok, and S. B. Tallman, Resources, transactions, and rents: Managing value through interfirm collaborative relationships, Organization Science, 9, 1996, 326-339.

[24] P. Hwang, Transaction threshold social capital and utopia, Working paper National University of Singapore, 2009.

[25] F. Welter, T. Kautonen, A. Chepurenko, E. Malieva, and U. Venessar, Does trust matter? A cross-cultural view on entrepreneurship in different trust milieus, Proc. $23^{\text {rd }}$ annual entrepreneurship research conference on Frontiers of entrepreneurship research, MA: Babson College, 2003.

[26] G. Hofstede, Cultures and organizations: Software of the mind, (Berkshire, England: McGraw-Hill, 1991, P. 51).

[27] H. C. Triandis, Collectivism and individualism as cultural syndromes, Cross-cultural Research, 27, 1993, 155-180.

[28] J. M. Hagen, and S. Choe, Trust in Japanese interfirm relations: Institutional sanctions matter, Academy of Management Review, 23 (3), 1998, 589-600. 